\title{
Endoscopic removal of tubulovillous adenoma with high grade focal dysplasia in the distal common bile duct
}
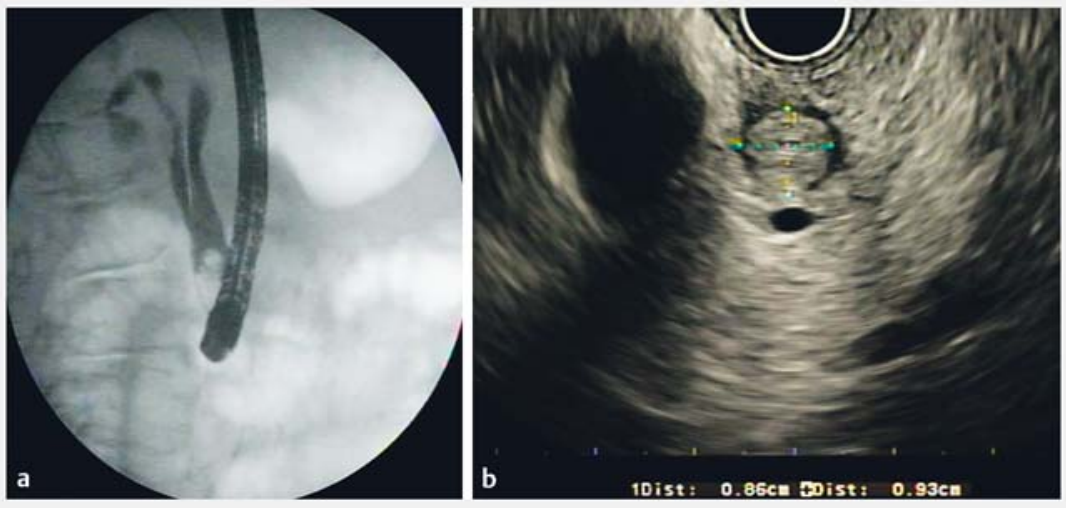

- Fig. 1 Initial imaging. a Endoscopic retrograde cholangiopancreatography showed a filling defect at the distal common bile duct. $\mathbf{b}$ An endoscopic ultrasound revealed the presence of a $10 \times 8 \mathrm{~mm}$ polyp.
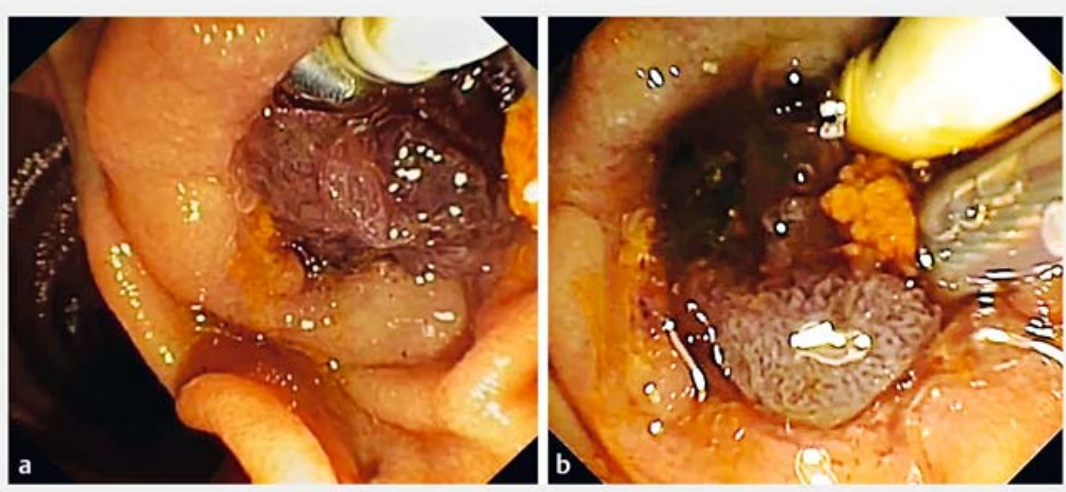

- Fig. 2 Removal of the polyp. a Using a Fogarty balloon, the polyp was tractioned toward the duodenum. b Polypectomy was performed using a pediatric hot snare.

An 80-year-old woman with pluripathology was admitted with cholangitis. A computed tomography scan showed a dilated common bile duct (CBD) and a possible distal choledocholithiasis. An endoscopic retrograde cholangiopancreatography was performed and the duct was swept with a balloon, revealing a polypoid lesion of adenomatous appearance through the papilla. The pathology confirmed a tubulo-villous adenoma with high grade focal dysplasia. An endoscopic ultrasound revealed the presence of a $10 \times 8 \mathrm{~mm}$ polyp in the CBD ( $\vee$ Fig. 1). As the patient was a high risk surgical candidate, endoscopic treatment was indicated in accordance with a multidisciplinary committee.

The papilla was reached using the duodenoscope and a papilloplasty was performed with a 12-mm pneumatic balloon ( $\vee$ Video 1). With the help of the Fogarty balloon and a biopsy forceps, the polyp was tractioned toward the duodenum and polypectomy was performed using a pediatric hot snare ( $\triangleright$ Fig. 2 ). Then, a ful-

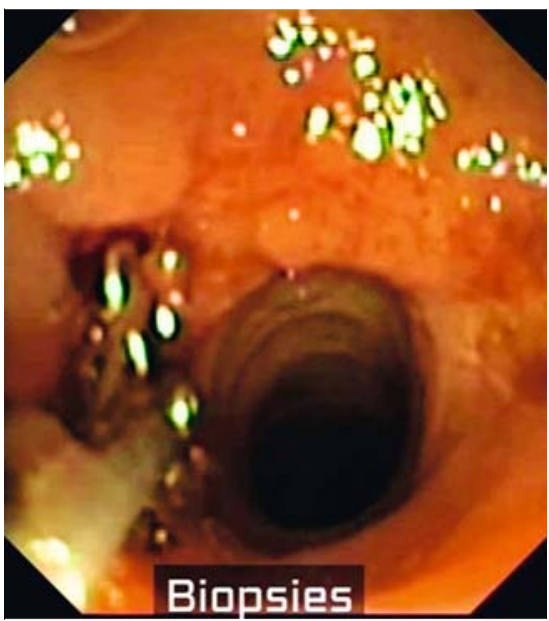

- Fig. 3 No remaining polyp was seen with a baby scope cholangioscopy at the 6-month follow-up visit. Pathology confirmed the absence of adenoma at 2 and 6 months.

guration soft coagulation was done and a fully covered self-expanding metallic biliary stent was placed.

After a 2-month follow-up period, a baby scope cholangioscopy showed no macroscopic lesion after removing the stent. In addition, fulguration with argon beam was applied to the polypectomy site. In the next follow-up at 6 months, a baby scope cholangioscopy showed no remaining polyp ( $>$ Fig.3). Pathology confirmed the absence of adenoma at 2 and 6 months. No complications were detected during follow-up.

Adenomas of the extrahepatic bile duct are uncommon benign neoplasms with an unknown malignant potential [1-3]. Surgery is the current treatment [1-3], with only five published cases of successful endoscopic treatment in nonsurgical patients [2]. In the current case, the key to achieving technical success was good visualization through the papilla (papilloplasty+stent) and the use of a pediatric polypectomy snare with the help of the balloon. 


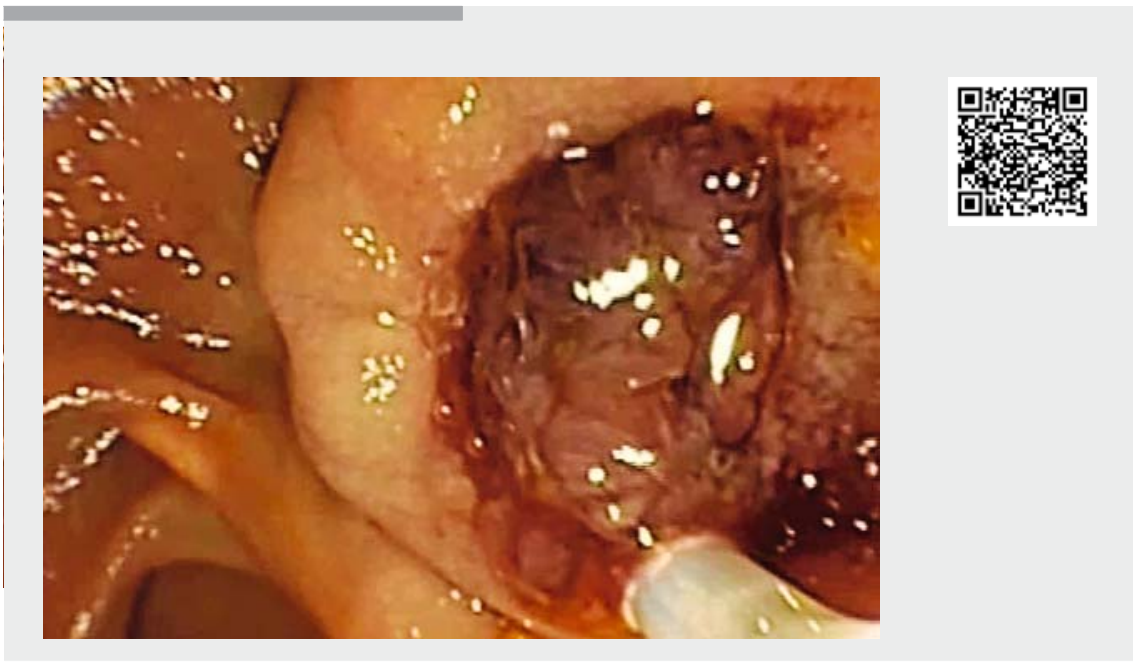

Video 1 Endoscopic removal of a tubulovillous adenoma with high grade focal dysplasia in the distal common bile duct.

Endoscopy_UCTN_Code_TTT_1AR_2AF

Competing interests

None

The authors

Rogger Alvaro Bendezú-García ${ }^{1,2}$, Xavier Andújar-Murcia ${ }^{1,3}$, Carme Loras ${ }^{1,3}$

1 Department of Gastroenterology, Hospital Universitari MútuaTerrassa, Fundació per la Recerca Mútua Terrassa, Terrassa, Catalonia Spain

2 Department of Gastroenterology, Hospital Universitari General de Catalunya, Catalonia, Spain

3 Centro de Investigación Biomédica en Red de Enfermedades Hepáticas y Digestivas (CIBERehd), Spain

\section{Corresponding author}

\section{Carme Loras, MD, PhD}

Department of Gastroenterology, Endoscopy Unit, Hospital Universitari Mútua Terrassa, Universitat de Barcelona, Plaça Dr Robert n 5, 08221 Terrassa, Barcelona, Catalonia, Spain

Fax: +34-93-7365043

cloras@mutuaterrassa.cat

\section{References}

[1] Burhaus R, Myers RT. Benign neoplasms of the extrahepatic biliary ducts. Am Surg 1971; 37: 161-166

[2] Loh K, Nautsch D, Mueller J et al. Adenomas involving the extrahepatic biliary tree are rare but have an aggressive clinical course. Endosc Int Open 2016; 4: E112-E117

[3] Munshi AG, Hassan MA. Common bile duct adenoma: case report and brief review of literature. Surg Laparosc Endosc Percutan Tech 2010; 20: e193-e194

\section{Bibliography}

DOI https://doi.org/10.1055/a-0915-1638

Published online: 4.6.2019

Endoscopy 2019; 51: E319-E320

(C) Georg Thieme Verlag KG

Stuttgart · New York

ISSN 0013-726X

\section{ENDOSCOPY E-VIDEOS}

https://eref.thieme.de/e-videos

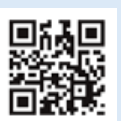

Endoscopy E-Videos is a free access online section, reporting on interesting cases and new techniques in gastroenterological endoscopy. All papers include a high quality video and all contributions are freely accessible online.

This section has its own submission website at https://mc.manuscriptcentral.com/e-videos 